\title{
COMPOSTOS BIOATIVOS E ATIVIDADE ANTIOXIDANTE DO CAFÉ (Coffea arabica L.)
}

\author{
Coffee (Coffea arabica L.) bioactive compounds and antioxidant activity
}

\author{
Sheila Andrade Abrahão ${ }^{1}$, Rosemary Gualberto Fonseca Alvarenga Pereira ${ }^{2}$, Stella Maris da Silveira Duarte ${ }^{3}$, \\ Adriene Ribeiro Lima ${ }^{2}$, Dalila Junqueira Alvarenga ${ }^{4}$, Eric Batista Ferreira ${ }^{5}$
}

\begin{abstract}
RESUMO
Conduziu-se este trabalho, com a proposta de avaliar o potencial antioxidante de dois padrões da bebida do café (rio e mole), verdes e torrados, utilizando modelos in vitro. Foram determinados o teor de fenólicos totais, ácido clorogênico (ácido 5-cafeoilquínico) e cafeína das bebidas. A avaliação in vitro do potencial antioxidante foi investigada pelos métodos de captação do radical DPPH e pelo poder redutor de metais. Os dois padrões de bebida do café analisados não apresentaram diferenças quanto aos parâmetros cor, ácido clorogênico e cafeína. Observou-se que houve redução nos valores de ácido clorogênico à medida que os grãos foram torrados. O café verde bebida rio apresentou maior teor de fenólicos totais que o café bebida mole. Nos grãos torrados não foi observada diferença. A bebida do café independente da qualidade sensorial apresentou alto poder redutor e importante atividade sequestrante de radicais livres. A atividade sequestrante de radicais livres foi significativamente superior nas amostras obtidas a partir dos grãos torrados, quando comparados aos extratos dos grãos verdes. A torração, porém, reduziu o poder redutor das bebidas do café. Os dados obtidos permitem sugerir que, independente da classificação sensorial da bebida, o café apresenta expressiva capacidade sequestrante de radicais livres e poder redutor de metais.
\end{abstract}

Termos para indexação: Qualidade da bebida, compostos fenólicos, ácido clorogênico, cafeína, capacidade antioxidante, poder redutor.

\begin{abstract}
The present work intended to evaluate the antioxidant potential of two coffee sorts (soft and river), green and roasted, in vitro. Phenolic compounds content, chlorogenic acid (5-cafeoyolquinic) and caffeine of the beverages were evaluated. In vitro evaluation of the antioxidant potential was investigated by DPPH radical scavenging assay and by reducing the power of metals. Both sorts of coffee did not present statistical differences for color, chlorogenic acid and caffeine. After roasting, 5-cafeoyolquinic acid levels decreased. River coffee beverage presented greater content of phenolics than the soft coffee beverage. In the roasted coffees no significant difference was observed. All sorts of coffee beverages presented high reducing ability and important scavenging activity of free radicals. The scavenging activity was higher in the roasted samples. The roast process decreased the reducing ability of the coffee beverage. Results allow suggesting that independent of the sort, coffee presents expressive antioxidant activity and reducing ability.
\end{abstract}

Index terms: Beverage quality, phenolic compounds, chlorogenic acid, caffeine, antioxidant capacity, reducing power.

(Recebido em 4 de julho de 2008 e aprovado em 28 de abril de 2009)

\section{INTRODUÇÃO}

$\mathrm{Na}$ última década, a demanda por cafés diferenciados intensificou-se e o setor cafeeiro vem investindo, cada vez mais, na produção de cafés com qualidade em razão da exigência do mercado consumidor (Mendonça et al., 2007). Para se enquadrar nesse novo cenário, os produtores necessitam, cada vez mais, dedicar grande atenção às diversas etapas da produção como condução da lavoura, colheita e pós-colheita, já que os atributos físicos e sensoriais de sabor e aroma, influenciados por estes processos, são decisivos para a classificação dos cafés.

A classificação oficial da bebida do café é realizada, após a degustação da amostra por provadores treinados que podem enquadrá-la em classes superiores como estritamente mole, mole e apenas mole, classe intermediária como a bebida dura, ou classes inferiores como bebida riada, rio e rio zona (Brasil, 2007).

As diferenças na composição química e características dos grãos de café beneficiado contribuem para que os mesmos, quando submetidos ao processo de torração forneçam bebidas com características sensoriais diferenciadas (BORÉM et al., 2008). Inúmeros trabalhos tentam correlacionar a qualidade final da bebida do café com a composição química do grão verde, sugerindo que cafés de qualidade inferior apresentam menores teores de açúcares e proteínas e maiores de acidez total titulável e, principalmente, teores de compostos fenólicos, porém os

\footnotetext{
1Universidade Federal de Lavras/UFLA - Departamento Ciência dos Alimentos/DCA - Cx. P. 3037 - 37200-000 - Lavras, MG - sheilanutri@yahoo.com.br 2Universidade Federal de Lavras/UFLA - Departamento Ciência dos Alimentos/DCA - Lavras, MG

${ }^{3}$ Universidade Federal de Alfenas/Unifal - Departamento Análises Clínicas - Alfenas, MG

${ }^{4}$ Universidade Federal de Alfenas/Unifal - Alfenas, MG

${ }^{5}$ Universidade Federal de Lavras/UFLA - Departamento de Ciências Exatas/DEX - Lavras, MG
} 
resultados ainda não são conclusivos(Bassoli, 1992; Pereira, 1997; Pinto et al., 2001).

Os compostos fenólicos, além de serem relatados como contribuintes do sabor e aroma característicos das bebidas de café, são conhecidos em razão das propriedades fisiológicas e farmacológicas que conferem à saúde humana, como a atividade antioxidante. Entre os principais componentes da fração fenólica figuram os ácidos clorogênicos (CGA), na forma de diversos isômeros, considerados os mais importantes e os que se apresentam em maior quantidade nos grãos de café verde. A atividade antioxidante de compostos fenólicos deve-se, principalmente, às suas propriedades redutoras e estrutura química. Essas características desempenham um papel importante na neutralização de radicais livres e quelação de metais de transição, agindo tanto na etapa de iniciação como na propagação do processo oxidativo. Os intermediários formados pela ação de antioxidantes fenólicos são relativamente estáveis, em razão da ressonância do anel aromático presente na estrutura dessas substâncias. Embora as evidências sejam claras sobre a ação in vitro dos fenóis e polifenóis sobre espécies reativas de oxigênio, eles podem, em algumas circunstâncias, tal como o ascorbato e os carotenóides, apresentarem ação pró-oxidante (Farah \& Donangelo, 2006; Souza et al., 2007).

Daglia et al. (2000) afirmaram que apesar de alguns compostos fenólicos serem destruídos com a torração, participam da reação de Maillard, originando vários produtos. Esses produtos também podem apresentar propriedades antioxidantes, com mecanismos de ação que envolvem a quelação de metais, interrupção de reações em cadeia pela doação de um átomo de hidrogênio, reduzindo hidroperóxidos a produtos não radicalares e captura do radical hidroxil (Daglia et al., 2000; Borrelli et al., 2002; Adams et al., 2005).

Em contrapartida, já foi constatado que a torração possibilita a formação de acrilamida (ACM), o qual apresenta uma potencial atividade cancerígena aos humanos (Neri, 2004). Além disso, alguns estudos epidemiológicos têm evidenciado a ausência de benefícios, e até mesmo o efeito deletério da bebida do café, sendo associado ao desenvolvimento de diferentes tumores (Higdon \& Frei, 2006).

O café constitui uma bebida de grande popularidade, que é consumida mundialmente, com aroma e sabor característicos. Em vista disso, numerosos estudos concernentes a sua segurança e as implicações da sua bebida na saúde têm sido realizados. A esta bebida, em função de sua composição química, têm sido atribuídas inúmeras vantagens e desvantagens para a saúde humana. Por outro lado, pouco se sabe se os cafés de qualidade superior exercem os mesmos efeitos que os cafés de qualidade inferior. Neste estudo, objetivou-se quantificar alguns dos compostos bioativos e analisar a atividade antioxidante in vitro de cafés de qualidade diferenciada.

\section{MATERIAL E MÉTODOS}

\section{Obtenção das amostras de café}

Foram utilizadas amostras de café (Coffea arabica L.), provenientes da safra 2005/06 do sul de Minas Gerais, fornecidas por uma empresa de comercialização do município de Alfenas- MG.

\section{Preparo da amostra}

Amostras de cafés foram torradas em torrador de laboratório com capacidade para $1 \mathrm{~kg}$, no grau de torração médio. $\mathrm{O}$ ponto ideal de torração foi determinado pelo binômio tempo/temperatura $\left(180^{\circ} \mathrm{C}\right.$ por 10 minutos $)$ e a cor do café foi analisada, usando-se um colorímetro (Chomameter-2 Reflectance, Minolta, Osaka, Japan). Em seguida, os grãos torrados foram moídos (moinho elétrico Pinhalense, ML-1, Brasil) até granulometria fina (20 mesh), empacotados em 6 embalagens de $500 \mathrm{~g}$ de polietileno/ alumínio, selados e armazenados a $-20^{\circ} \mathrm{C}$, até o uso.

Os grãos verdes foram moídos até granulometria fina em moinho refrigerado a $4^{\circ} \mathrm{C}$ (Tecnal, modelo TE 631/2, Brasil) com auxílio de nitrogênio líquido, empacotados em 6 embalagens de $500 \mathrm{~g}$ de polietileno/alumínio, selados e armazenados $\mathrm{a}-20^{\circ} \mathrm{C}$, até o uso.

\section{Análise sensorial}

A análise sensorial foi realizada por meio do método oficial brasileiro de classificação do café pela bebida, segundo a Instrução Normativa n. 8, de 11 de junho de 2003 do Ministério da Agricultura, Pecuária e Abastecimento, conhecido como prova da xícara(Brasil, 2007). Após a análise, foram selecionadas para o experimento as amostras classificadas como bebida mole e bebida rio.

\section{Preparo da bebida}

Dez gramas de pó de café (verde e torrado) foram colocados em filtro de papel n. 3 e, em seguida, foram vertidos $100 \mathrm{~mL}$ de água destilada, a $90^{\circ} \mathrm{C}$, sobre o pó contido no filtro. Todos os experimentos foram realizados com bebida preparada no momento de uso (Duarte, 2005).

\section{Determinação do teor de compostos fenolicos totais}

A determinação dos fenólicos totais na bebida do café foi realizada pelo método de Folin Denis, descrito pela Association of Official Agriculture Chemists-AOAC (1990). 
Transferiu-se $0,1 \mathrm{~mL}$ das bebidas dos cafés já preparadas para tubos de ensaio devidamente identificados. Posteriormente, foram adicionados $8,4 \mathrm{~mL}$ de água destilada, $0,5 \mathrm{~mL}$ de reagente Folin-Denis e $1 \mathrm{~mL}$ de solução de carbonato de sódio a $4 \%(\mathrm{~m} / \mathrm{v})$, os tubos foram agitados e mantidos à temperatura ambiente por $30 \mathrm{~min}$. Decorrido o tempo, a absorbância foi determinada em $760 \mathrm{~nm}$ (Espectrofotômetro Shimadzu, UV-1601, Japão). A concentração de fenólicos totais foi calculada utilizando-se ácido gálico como padrão.

\section{Determinação dos teores de cafeína e ácido 5 - cafeoilquínico}

Para determinação de cafeína e ácido 5cafeoilquínico, foram utilizados procedimentos de extração com água quente, segundo Vitorino et al. (2001), com diluição de $0,5 \mathrm{~g}$ de pó de café $/ 100 \mathrm{~mL}$ de água destilada e análise por cromatografia líquida de alta eficiência (CLAE), utilizando-se cromatógrafo da marca Shimadzu (modelo M10AVP, Japão) com coluna de fase reversa C-18 Shimadzu (100 mm x $0.3 \mathrm{~mm})$. O sistema encontrava-se acoplado a um detector espectrofotométrico UV/visível Shimadzu (modelo SPD-10A) conectado por uma interface (CBM-101) a um microcomputador para processamento de dados. As condições de análise foram fluxo de $1 \mathrm{~mL} / \mathrm{min}$; fase móvel: metanol, água e ácido acético (20:80:1); temperatura ambiente; comprimento de onda $272 \mathrm{~nm}$. A concentração dos compostos foi determinada pela relação entre as áreas dos picos de cafeína e ácido 5-cafeoilquínico da amostra e dos respectivos padrões de concentrações conhecidas.

\section{Atividade sequestrante de radicais livres DPPH}

Para a análise da atividade sequestrante de radicais livres DPPH (1,1-difenil-2-picrilhidrazil) da bebida de café, cada amostra foi diluída em etanol a 25, 50, 100, $200 \mu \mathrm{g} \cdot \mathrm{mL}^{-1}$. Em $4 \mathrm{~mL}$ da amostra, foi adicionado $1 \mathrm{~mL}$ de DPPH $(0,5$ mmol. $\left.L^{-1}\right)$ igualmente diluído em etanol. A mistura foi acondicionada em tubo de ensaio âmbar e agitada. Decorridos $30 \mathrm{~min}$, foi realizada a leitura a $517 \mathrm{~nm}$ (Espectrofotômetro Shimadzu, UV-1601, Japão). A diminuição na absorbância indica atividade sequestrante de radicais livres. Os testes foram realizados em triplicata. A atividade sequestrante de radicais livres (ASRL) foi expressa em porcentagem por comparação ao controle, BHT (butil-hidróxi-tolueno) nas mesmas diluições das amostras de café, segundo a equação:

$$
\% \text { ASRL }=\frac{A c-A t}{A c} \times 100
$$

onde, Ac: absorbância do controle; At: absorbância do teste (amostra).

\section{Avaliação do poder redutor}

Alíquotas de $0,01 \mathrm{~mL}$ da bebida do café, na concentração final de 200 ppm, foram diluídas em $1 \mathrm{~mL}$ de etanol absoluto e transferidas para tubo de ensaio contendo 2,5 mL de tampão fosfato $0,2 \mathrm{M} \mathrm{pH} \mathrm{6,6} \mathrm{e} \mathrm{2,5} \mathrm{mL} \mathrm{de}$ ferricianeto de potássio a $1 \%(\mathrm{~m} / \mathrm{v})$. A mistura foi incubada em banho-maria a $45^{\circ} \mathrm{C}$, por 20 minutos. Alíquotas de 2,5 $\mathrm{mL}$ de ácido tricloroacético a $10 \%(\mathrm{~m} / \mathrm{v})$ foram adicionadas ao tubo de ensaio, com posterior agitação. Alíquotas de $2,5 \mathrm{~mL}$ da mistura foram transferidas para outro tubo de ensaio, ao qual foram adicionados $2,5 \mathrm{~mL}$ de água destilada e $0,5 \mathrm{~mL}$ de $\mathrm{FeCl}_{3}$ a $0,1 \%(\mathrm{~m} / \mathrm{v})$, com posterior agitação. A leitura da absorbância foi realizada a $700 \mathrm{~nm}$ (Espectrofotômetro Shimadzu, UV-1601, Japão). A atividade redutora da bebida foi expressa como porcentagem de inibição em comparação ao BHT, usado como padrão.

\section{Análise estatística}

O delineamento experimental utilizado foi o inteiramente casualizado com parcelas subdivididas. Para os parâmetros compostos fenólicos totais, cafeína, ácido 5-cafeoilquínico e poder redutor, utilizaram-se 4 tipos de café (café cru bebida rio, café torrado bebida rio, café cru bebida mole e café torrado bebida mole) e 6 repetições para cada tratamento.

Para a atividade sequestrante de radicais livres foram utilizados 4 tipos de bebida (café cru bebida rio, café torrado bebida rio, café cru bebida mole e café torrado bebida mole), 4 concentrações $\left(25,50,100,200 \mu \mathrm{g} \cdot \mathrm{mL}^{-1}\right) \mathrm{e}$ 3 repetições para cada tratamento.

Os dados obtidos foram submetidos à análise de variância (anava) e comparados pelo teste de Tukey, quando $\mathrm{p}<0,05$. Os resíduos da anava podem ser considerados normais de acordo com o teste de ShapiroWilk, a 5\% de significância.

\section{RESULTADOS E DISCUSSÃO}

\section{Compostos fenólicos Totais}

Determinou-se o teor de compostos fenólicos totais dos diferentes extratos de café obtidos. Os valores percentuais médios das determinações dos compostos fenólicos totais dos cafés in natura (verdes) e dos cafés torrados são apresentados na Tabela 1

Existem indícios de ocorrência de maior concentração de compostos fenólicos totais em cafés de pior qualidade. Pinto et al. (2001), estudando grãos de café arábica da região sul de Minas Gerais, previamente classificados em diferentes padrões de bebidas, encontrou maior teor de compostos fenólicos 
totais nos cafés de bebida rio, quando comparados aos cafés classificados como bebida mole. No presente estudo, a bebida de pior qualidade analisada (bebida rio) também apresentou um maior teor de compostos fenólicos totais $(5,43 \%)$ do que o café de qualidade superior (bebida mole), com $4,77 \%$ nas amostras verdes $(\mathrm{p}<0,05)$.

Tabela 1 - Conteúdo de compostos fenólicos totais (g eq. ac. gálico / 100g) de dois tipos de bebida do café submetido a dois tipos de processamento.

\begin{tabular}{ccc}
\hline & \multicolumn{2}{c}{ Processamento } \\
\cline { 2 - 3 } Tipo de bebida & Verde & Torrado \\
\hline Rio & $5,43 \mathrm{aA}$ & $4,83 \mathrm{aB}$ \\
Mole & $4,77 \mathrm{bA}$ & $4,51 \mathrm{aA}$ \\
\hline
\end{tabular}

Médias seguidas por letras minúsculas iguais dentro de cada coluna e seguidas por letras maiúsculas iguais dentro de cada linha não diferem entre si $(\mathrm{p}>0,05)$, pelo teste de Tukey.

De acordo com os dados expressos na Tabela 1, no grão verde, houve uma variação significativa, nos teores de fenólicos entre os distintos padrões de bebidas analisados, o que não ocorreu com os grãos torrados. A bebida rio destacou-se com o maior teor de fenólicos no grão verde e maior perda desses compostos com a torração. A bebida mole, apesar de apresentar um teor de compostos fenólicos totais mais baixo, demonstrou uma maior termoestabilidade, ou seja, menor perda desses compostos durante a torração.

Os resultados obtidos apresentam-se próximos ao intervalo de 4,31 a 6,18 \% citados por Fernandes et al. (2003), para cafés verdes e torrados da espécie Coffea arabica L. da região sul de Minas Gerais e inferiores aos encontrados por Vilela (2002) em cafés cereja descascados $(7,54 \%)$.

\section{Cafeína e ácido 5-cafeoilquínico}

Os teores de ácido 5-cafeoilquínico e cafeína foram calculados, a partir dos cromatogramas obtidos para cada amostra. Os tempos de retenção correspondentes aos compostos de interesse foram: ácido clorogênico 16 minutos e cafeína $\sim 17$ minutos.

Analisando os teores de ácido 5-cafeoilquínico encontrados (Figura 1), observou-se que, para todas as classes de bebida, houve redução nos valores, à medida que os grãos foram torrados, confirmando a influência do processo de torração na composição qualitativa e quantitativa. (Rodarte et al.,2009).

Segundo Araújo (2007), o conteúdo total de ácido 5cafeoilquínico em café arábica é de $5,5 \mathrm{~g} .100 \mathrm{~g}^{-1}$, valores esses próximos ao encontrado neste estudo para o padrão de bebida mole e superior ao apresentado pelo café bebida rio.

Quanto à cafeína, para os dois tipos de bebidas avaliados não houve diferença significativa entre os valores, tanto nos grãos verdes, quanto nos torrados (Figura 1).

A cafeína foi o composto que apresentou maior estabilidade à torração. Os valores encontrados foram semelhantes aos observados por Monteiro \& Trugo (2005), os quais, estudando dez amostras de café comerciais do Brasil encontraram variação de 0,8 a 1,4\%.

Considerando que, tanto o ácido 5-cafeoilquínico, como a cafeína vêm sendo indicados como compostos com potencial atividade antioxidante (Nicoli et al., 1997; Lee, 2000; Iwai et al., 2004; Duarte et al., 2005), os resultados encontrados na análise cromatográfica sugerem que os cafés torrados amostrados possuem estatisticamente o mesmo poder de proteção contra danos oxidativos.

\section{Atividade seqüestrante de radicais livres}

Na Tabela 2, estão representados os resultados da análise da atividade antioxidante das bebidas de café, utilizando o radical livre DPPH. O composto utilizado como padrão foi o butil-hidroxi-tolueno (BHT), o qual apresentou atividade sequestrante de radicais livres, na concentração de 200 ppm, de $76,8 \%$.

Os resultados da Tabela 2 permitem verificar que, para as bebidas dos cafés nas concentrações de 50, 100 e 200 ppm, a atividade sequestrante de radicais livres foi significativamente superior nas amostras obtidas, a partir dos grãos torrados, quando comparados aos extratos dos grãos verdes.

Neste estudo, as amostras foram comparadas em concentrações que são até oito vezes menores que a concentração máxima usada pela indústria alimentícia (200 ppm) para antioxidantes. Nas concentrações mais elevadas, as amostras de café apresentaram uma porcentagem de inibição da oxidação semelhante ao antioxidante de referência (BHT), evidenciando a eficiência do café no combate à ação dos radicais livres $(\mathrm{p}<0,05)$. As bebidas analisadas demonstraram maior atividade antioxidante na concentração de 200 ppm, diminuindo significativamente em concentrações menores.

Pode-se notar que entre os dois padrões de bebidas analisados não houveram diferenças estatisticamente significativas e que ambos apresentaram relevantes percentuais de captação de radicais livres.

Araújo (2007) e Duarte et al. (2005), utilizando a mesma metodologia para avaliar a atividade sequestrante de radicais livres de amostra de café, obtiveram valores na 
faixa de $82,00 \%$ a $92,52 \%$, respectivamente, para a concentração de 200 ppm, valores estes superiores aos obtidos neste trabalho.

\section{Poder redutor}

As médias dos valores obtidos na análise do poder redutor das bebidas de café amostradas estão apresentadas na Tabela 3.

De acordo com a Tabela 3, nota-se que o tipo de bebida nos dois processamentos (verde e torrado) analisados, não influenciaram na capacidade redutora dos cafés ( $p>0,05)$. A torração, porém, reduziu o poder redutor das bebidas do café. Esses resultados, contrariam os apresentados por Daglia et al. (2000), que não encontraram alterações significativas no poder redutor com a torração para café arábica e corroboram com os encontrados por Santos et al. (2007), onde as amostras de grau escuro apresentaram menor poder redutor que as amostras com grau de torrefação claro. Segundo os autores, essa diminuição ocorre, provavelmente, em razão do diferente conteúdo de fenólicos totais nessas amostras, particularmente reduzidos, após a torrefação.

$\mathrm{Na}$ análise do poder redutor, opostamente ao encontrado na análise da atividade sequestrante de radicais livres, os cafés verdes demonstraram maior atividade antioxidante que os torrados. Nota-se que a atividade antioxidante das amostras analisadas variou conforme a metodologia utilizada, o que demonstra a importância da realização de mais de uma análise para que se tenha uma maior confiabilidade dos resultados. É importante ressaltar que, dependendo do meio e da reação, o mesmo composto pode apresentar um comportamento antioxidante diferente ou até mesmo próoxidante.

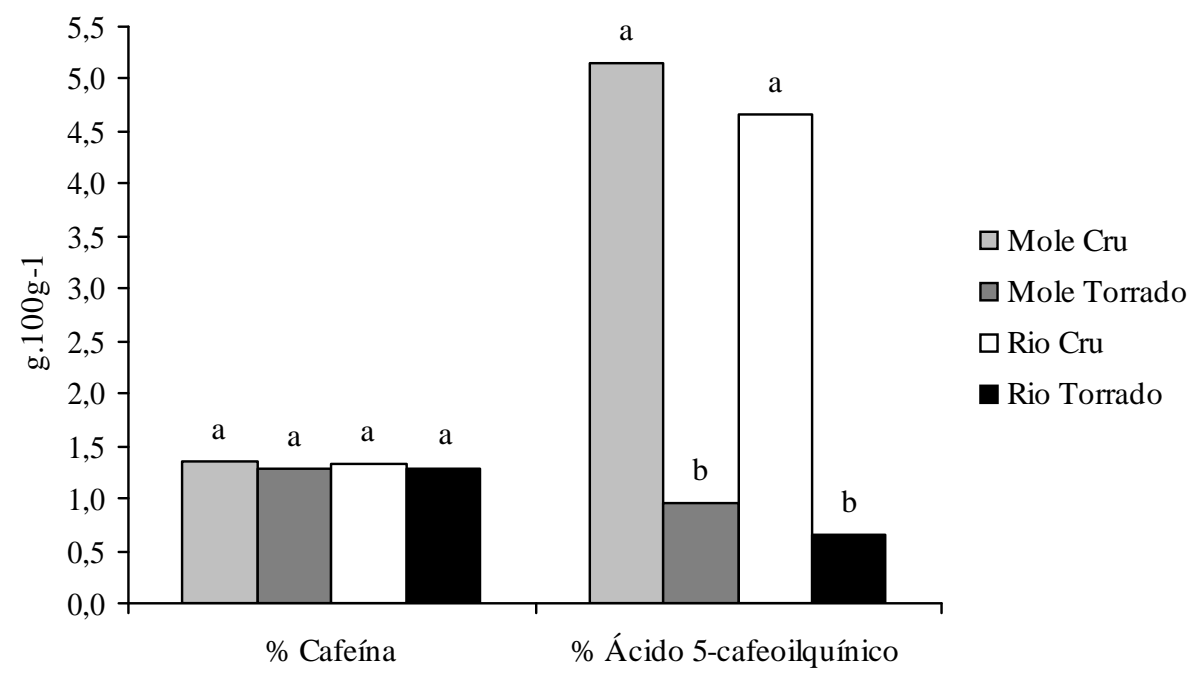

Figura 1 - Teores médios de ácido 5-cafeoilquínico e cafeína em cafés bebida mole e rio submetidos a dois tipos de processamento (verde e torrado). Médias seguidas por letras diferentes diferem entre si $(\mathrm{p}<0,05)$, pelo teste de Tukey.

Tabela 2 - Atividade sequestrante do radical DPPH (\%) das bebidas de café rio e mole, in natura e torrado, em quatro concentrações.

\begin{tabular}{ccccc}
\hline & \multicolumn{4}{c}{ Concentração $(\mathrm{ppm})$} \\
\cline { 2 - 5 } Tipo de bebida & 25 & 50 & 100 & 200 \\
\hline Rio torrado & $40,13 \mathrm{aD}$ & $53,60 \mathrm{aC}$ & $60,60 \mathrm{aB}$ & $76,30 \mathrm{aA}$ \\
Rio verde & $36,37 \mathrm{aC}$ & $45,93 \mathrm{bB}$ & $48,00 \mathrm{bB}$ & $68,87 \mathrm{bA}$ \\
Mole torrado & $44,67 \mathrm{aD}$ & $58,37 \mathrm{aC}$ & $64,33 \mathrm{aB}$ & $77,27 \mathrm{aA}$ \\
Mole verde & $39,93 \mathrm{aC}$ & $46,47 \mathrm{bB}$ & $49,50 \mathrm{bB}$ & $69,00 \mathrm{bA}$ \\
\hline
\end{tabular}

Médias seguidas por letras minúsculas iguais dentro de cada coluna e médias seguidas por letras maiúsculas iguais dentro de cada linha não diferem entre si pelo teste de Tukey $(\mathrm{p}=0,05)$. 
Tabela 3 - Poder redutor (\%) do café bebida rio e bebida mole, verde e torrado.

\begin{tabular}{ccc}
\hline & \multicolumn{2}{c}{ Processamento } \\
\cline { 2 - 3 } Tipo de Bebida & Verde & Torrado \\
\hline Rio & $46,83 \mathrm{aA}$ & $28,68 \mathrm{bB}$ \\
Mole & $44,30 \mathrm{aA}$ & $31,74 \mathrm{bB}$ \\
\hline
\end{tabular}

Médias seguidas por letras minúsculas iguais dentro de cada coluna e seguidas por letras maiúsculas iguais dentro de cada linha não diferem entre si ( $p>0,05)$, pelo teste de Tukey.

\section{CONCLUSÕES}

O café torrado possui menores valores de compostos fenólicos totais e maiores teores de ácido 5cafeoilquínico comparados ao café verde analisado.

O teor de compostos fenólicos totais é superior nos cafés de pior qualidade. Já os teores de ácido 5cafeoilquínico e cafeína são semelhantes para os dois tipos de bebida estudados.

Independente da classificação sensorial da bebida, os cafés, quando comparados ao antioxidante padrão BHT, apresentam expressiva capacidade sequestrante de radicais livres, com superioridade dos cafés torrados.

Os extratos dos cafés verdes analisados demonstraram maior poder redutor de metais que os dos cafés torrados.

\section{AGRADECIMENTOS}

Ao Conselho Nacional de Desenvolvimento Científico e Tecnológico - CNPq, pela concessão da bolsa de estudos e a Fundação de Amparo à Pesquisa do Estado de Minas Gerais - Fapemig, pelo financiamento do projeto.

\section{REFERÊNCIAS BIBLIOGRÁFICAS}

ADAMS, A.N.; BORRELLI, R.C.; FOGLIANO, V.; KIMPE, $\mathrm{N}$. Thermal degradation studies of food melanoidins, Journal of Agricultural and Food Chemistry, Washington, v.53, n.10, p.4136-4142, May 2005.

\section{ARAUJO, F.A. Café (Coffea arabica L.) submetido a diferentes condições de torrefação: caracterização química e avaliação da atividade antioxidante e sensorial. 2007. 130p. Tese (Doutorado)-Universidade de São Paulo, São Paulo, 2007.}

\section{ASSOCIATION OF OFFICIAL AGRICULTURAL CHEMISTS. Official methods of analysis of the Association of Official Agricultural Chemists. 12.ed. Washington, 1990.}

BASSOLI, P.G. Avaliação da qualidade de cafés verdes brasileiros: uma análise multivariada. 1992. 110p. Dissertação (Mestrado em Bioquímica)-Universidade Estadual de Londrina, Londrina, 1992.

BORÉM, F. M.; NOBRE, G. W.; FERNANDES, S. M.; PEREIRA, R. G. F. A.; OLIVEIRA, P. D. de. Avaliação sensorial do café cereja descascado, armazenado sob atmosfera artificial e convencional. Ciência e Agrotecnologia, Lavras, v.32, n.6, p. 1724-1729, nov./ dez., 2008.

BORRELLI, R.C.; VISCONTI, A.; MENNELLA, C.; ANESE, M.; FOGLIANO, V. Chemical characterization and antioxidant properties of coffee melanoidins. Journal of Agricultural and Food Chemistry, Washington, v.50, n.22, p.6527-6533, June 2002.

BRASIL. Ministério da Agricultura, Pecuária e Abastecimento. Instrução Normativa n. 8, de 11 de junho de 2003. Aprova o regulamento técnico da identidade e de qualidade para a classificação de café beneficiado grão cru. Brasília, 2003. Disponível em: বhttp://www.ministerio.gov.bri $>$. Acesso em: 20 jan. 2007.

DAGLIA, M.; PAPETTI, A.; GREGOTTI, C.; BERTÈ, F.; GAZZANI, G. In vitro antioxidant and ex vivo protetive activities of green and roasted coffee. Journal of Agricultural and Food Chemistry, Washington, v.48, n.5, p.1449-1454, May 2000.

DUARTE, S.M.S.; ABREU, C.M.P.; MENEZES, H.C.; SANTOS, M.H.; GOUVÊA, C.M.C.P. Effect of processing and roasting of the antioxidant activity of coffee brews. Ciência e Tecnologia de Alimentos, Campinas, v.25, n.2, p.387-393, abr./jun. 2005.

FARAH, A.; DONANGELO, C.M. Phenolic compounds in coffee. Brazilian Journal Plant of

Physiololy, Londrina, v.18, n.1, p.23-26, June/Mar. 2006.

FERNANDES, S.M.; PEREIRA, R.G.F.A.; PINTO, N.A.V.D.; NERY, F.C. Constituintes químicos e teor de extrato aquoso de cafés arábica (Coffea arabica L.) e conilon (Coffea canephora Pierre) torrados. Ciência Agrotecnologia, Lavras, v.27, n.5, p.1076-1081, set./out. 2003.

HIGDON, J.V.; FREI, B. Coffee and health: a review of recent human research. Critical Reviens in Food Science and Nutrition, Philadelphia, v.46, n.2, p.101-23, 2006. 
IWAI, K.; KISHIMOTO, N.; KAKINO, Y.; MOCHIDA, K.; FUJITA, T. In vitro antioxidant effects and tyrosinase inhibitory activities of seven hydroxycinnamoyl derivatives in green coffee beans. Journal of Agricultural and Food Chemistry, Washington, v.52, n.15, p.4893-4898, July 2004.

LEE, C. Antioxidant ability of caffeine and its metabolites based on the study of oxygen radical absorbing capacity and inhibition on LDL peroxidation. Clinica Chimica Acta, Amsterdam, v.295, n.1/2, p.141-154, May 2000.

MENDONÇA, L. M. V. L.; PEREIRA, R. G. F. A.; MENDES, A. N. G.; BORÉM, F. M.; MARQUES, E. R. Composição química de grãos crus de cultivares de Coffea arábica L. suscetíveis e resistentes à Hemileia vastatrix Berg et Br. Ciência e Agrotecnologia, Lavras, v. 31, n. 2, p. 413-419, mar./abr., 2007.

MONTEIRO, M.C.; TRUGO, L.C. Determinação de compostos bioativos em amostras comerciais de café torrado. Química Nova, São Paulo, v.28, n.4, p.637-641, jul./ago. 2005.

NERI, V.C.C. Acrilamida em alimentos: formação endógena e riscos à saúde. 2004. 72p. Dissertação (Mestrado em Vigilância Sanitária)-Fundação Osvaldo Cruz/Instituto Nacional do Controle de Qualidade em Saúde, Rio de Janeiro, 2004.

NICOLI, M.C.; ANESE, M.; MANZOCCO, L.; LERICE, C.R. Antioxidant properties of coffee brews in relation to the roasting degree. Lebensmittel - Wissenschaft und Technologie, London, v.30, n.2, p.292-297, 1997.

PEREIRA, R.G.F.A. Efeito da inclusão de grãos defeituosos na composição química e qualidade do café (Coffea arabica L. ) 'Estritamente Mole” 1997. 96p.
Tese (Doutorado em Ciência dos Alimentos)Universidade Federal de Lavras, Lavras, 1997.

PINTO, N.A.V.D.; FERNANDES, S.M.; PIRES, T.C.; PEREIRA, R.G.F.A.; CARVALHO, V.D. Avaliação dos polifenóis e açúcares em padrões de bebida do café torrado tipo expresso. Revista Brasileira de Agrociência, Pelotas, v.7, n.3, p.193-195, set./dez. 2001.

RODARTE, M. P.; ABRAHÃO, S. A.; PEREIRA, R. G. F. A., MALTA. M. R. Compostos não voláteis em cafés da região Sul de Minas submetidos a diferentes pontos de torração. Ciência e Agrotecnologia, Lavras, v. 33, n. 5, p. 1366-1371, set./out., 2009.

SANTOS, M.H.; BATISTA, B.L.; DUARTE, S.M.S.; LEMOS, B. Influence of processing and roasting on the antioxidant activity of cofee (Coffea arabica). Química Nova, São Paulo, v.30, n.3, p.604-610, maio/jun. 2007.

SOUZA, C.M.M.; SILVA, H.R.; VIEIRA-JUNIOR, G.M.; AYRES, C.L.S.C.; ARAUJO, D.S.; CAVALCANTE, L.C.D.; BARROS, E.D.S.; ARAUJO, P.B.M.; BRANDAO, M.S.; CHAVES, M.H. Fenóis totais e atividade antioxidante de cinco plantas medicinais. Química Nova, São Paulo, v.30, n.2, p.351-355, jul. 2007.

VILELA, T.C. Qualidade de café despolpado, desmucilado, descascado e natural, durante o processo de secagem. 2002. 66p. Dissertação (Mestrado em Ciência dos Alimentos)-Universidade Federal de Lavras, Lavras, 2002.

VITORINO, M.D.; FRANÇA, A.S.; OLIVEIRA, L.S.; BORGES, M.L.A. Metodologias de obtenção de extrato de café visando a dosagem de compostos não voláteis. Revista Brasileira de Armazenamento, Viçosa, v.26, n.3, p.17-24, 2001 